\title{
Study on the Effect of Waviness Guide Rail Error on the Precision of Linear Roller Bearings
}

\author{
[Sun-Woong Kwon, Tong Van Canh, Seong-Wook Hong*]
}

\begin{abstract}
Linear bearings are widely used to sustain positioning systems for machine tools. A linear bearing consists of a linear guide rail, rolling elements, and a carriage. For most positioning systems employing linear bearing, the guide rail error is closely related to the precision of the systems. In this study, the motion accuracy of linear roller bearings (LRBs) on the guide rail with vertical waviness error were investigated. To obtain the displacement of the carriage on the erroneous guide rail, a simulation model considering the contact surface deformation between the roller and carriage and between the roller and rail was developed. A flexible body model considering the carriage deformation due to contact load was also considered. The guide rail error was assumed to be harmonic with the period of consecutive clamping bolts because of bolt fastening to clamp the guide rail on the base. The contact loads of the LRBs were calculated with varying the amount of guide rail waviness error using the rigid body model, and the displacements due to the guide rail error was calculated. Then, to obtain the total displacement of the carriage, the elastic deformation of the carriage was calculated using the contact loads obtained from the rigid body model. The motion errors when the carriage moves along the guide rail with waviness error were calculated with varying the amount and period of waviness error. A rigorous investigation was made on the correlation between the carriage length and the interval of fastening bolts.
\end{abstract}

Keywords - linear roller bearing, carriage, guide rail, static deformation, contact load

\section{Introduction}

Linear bearings are widely used in machine tools to support loads or move objects precisely. Linear bearings consist of linear guide rails, carriages and rolling elements. Linear ball bearings are used when the moving speed is high with small load, while linear roller bearings are used when the supporting load is large. While linear bearings directly support the workpiece, it has weaker rigidity than other structures. Therefore it has a great influence on the precision of the machine. Rail errors are caused by various factors such as deformation due to bolting during rail fastening. uneven surface, and thermal deformation. Majda [1] proposed a geometric error of the guide rail in a linear roller bearing as a main source of the precision problem in machine tools. He simulated the geometric error as one of the volumetric errors

Sun-Woong Kwon, Seong-Wook Hong*

Kumoh National Institute of Technology, Republic of Korea

* Corresponding author

Tong Van Canh

Korea Institute of Machinery \& Materials, Republic of Korea of the machine tool. Khim, et al. [2] modeled a table with multiple linear bearings on errored guide rail. They estimated and compensated the guide rail error using transfer function method. Zhang, et al. [4] analyzed the error of the guide rail in the hydrostatic bearing and showed that the motion error is related to the spatial frequency of the guide rail error. Many researchers have studied on the guide rail error in linear ball bearings. However, there are few studies on linear roller bearings.

In this study, the effect of the guide rail error on the motion accuracy of the linear roller bearing was investigated.

\section{Linear bearing modeling}

In order to consider the effect of guide rail error on the linear bearing, the linear roller bearing model from Ref. [3] was used. Fig.1(a) shows the external force and corresponding displacement vectors in the global coordinate system of the linear roller bearing. The total displacement of the bearing is defined as the sum of the induced displacements from the rigid carriage model and the flexible carriage model. In the rigid body model, the carriage is assumed to be a rigid body, and the displacement is induced in the contact surface deformation between the carriage-roller and the roller-rail has illustrated in Fig.1(b).

In the flexible model, the displacement is induced from the elastic deformation of the carriage as shown in Fig.1(c).

The rigid body model assumes that the inertial effect due to the block motion is ignorable and the block and the rail excluding the contact point are sufficiently rigid. The displacement due to external loading is obtained by iterative

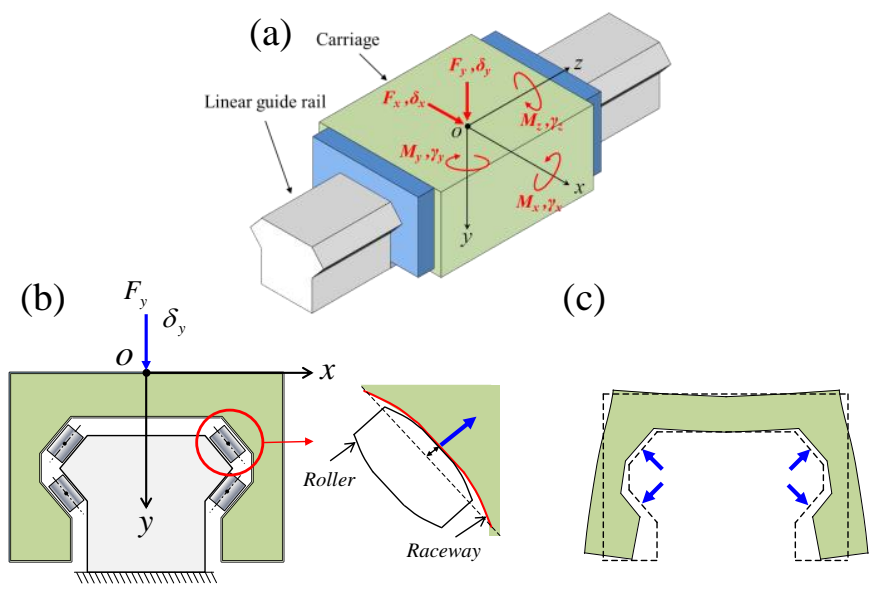

Figure 1. Linear roller bearing : a) External loads \& displacements, b) Rigid model, c) Felxible model 

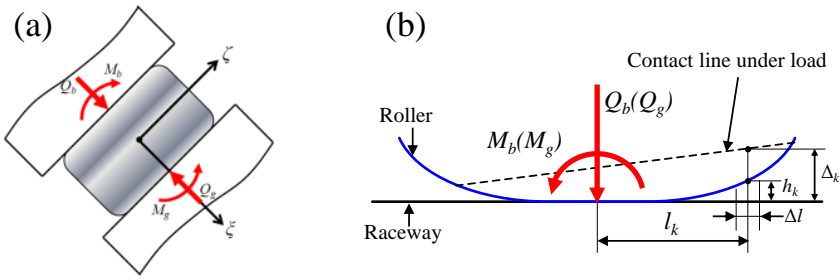

Figure 2. Roller equilibrium and contact load calculation with slicing method in the local coordinates system

calculation using the Newton-Raphson method to satisfy the equilibrium equations for the carriage and rollers. In the flexible model, the structure of the carriage is modeled using finite element method, and the contact load calculated in the rigid body model is applied to the roller contact surface. Then, the bearing displacement derived from the displacement of the roller contact surface is calculated.

\section{Roller equilibrium equation subjected to guide rail error}

In order to calculate the displacement of the bearing, the equilibrium equations associated with the forces resulting from the relative displacement of the carriage, roller and rail must be solved. Fig. 2 shows the free body diagram of a roller and the calculation of the roller contact load using the slicing method. Equation (1) is the roller equilibrium equation.

$$
\left\{\begin{array}{c}
Q_{b}-Q_{g}=0 \\
M_{b}-M_{g}=0
\end{array}\right.
$$

In this equation, the contact load $Q_{\mathrm{i}}(\mathrm{i}=\mathrm{b}, \mathrm{g})$ and the moment $M_{\mathrm{i}}(\mathrm{i}=\mathrm{b}, \mathrm{g})$ are expressed as the sum of the contact force and the moment calculated from one slice of the rail and the block contact surface as shown in Eq. (2).

$$
Q_{a}=\sum_{k=1}^{n_{e}} q_{k} \quad M_{a}=\sum_{k=1}^{n_{e}} q_{k} \times l_{k} \quad(\mathrm{a}=\mathrm{b}, \mathrm{g})
$$

where $n_{\mathrm{e}}$ is the number of slices. The compressive load of each slice is determined by the non-Hertzian load in Eq. (3), where $c$ is the contact constant, $\Delta_{k}$ is the compression amount of the contact surface, and $\Delta l$ is the slice length.

$$
\begin{gathered}
\left\{\begin{array}{cc}
q_{k}=c \times \Delta_{k}^{10 / 9} \Delta l & \left(\Delta_{k}>0\right) \\
q_{k}=0 & \left(\Delta_{k} \leq 0\right)
\end{array}\right. \\
\Delta_{k}=\left(u_{\xi}-v_{\xi}\right)+(\theta-\psi) l_{k}+\Delta_{0}-h_{k}
\end{gathered}
$$

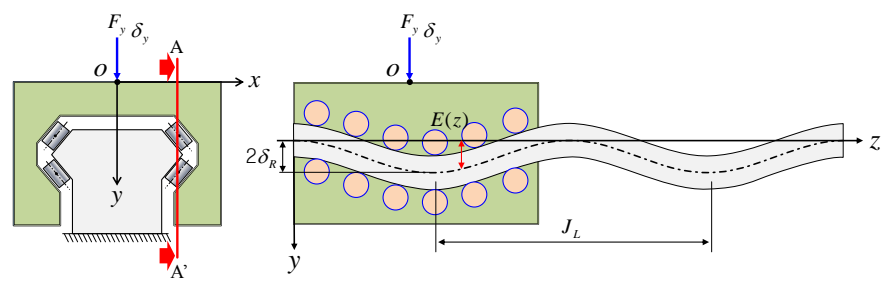

Figure 3. Waviness guide rail error on linear roller bearing

TABLE I. PARAMETERS OF LINEAR ROLLER BEARING

\begin{tabular}{|l|c|}
\hline \multicolumn{1}{|c|}{ Parameter } & Value \\
\hline Linear roller bearing model & INA, RUE35-E-HL \\
\hline Bearing length & $104 \mathrm{~mm}$ \\
\hline Effective roller length & $5.5 \mathrm{~mm}$ \\
\hline Roller diameter & $4.3 \mathrm{~mm}$ \\
\hline The number of roller & 24 \\
\hline Roller contact angle & $48^{\circ}$ \\
\hline
\end{tabular}

Equation (4) is the amount of compression in the carriageroller contact. $u$ and $v$ are the displacements of the block and roller cross sections in the local coordinate system, $\theta$ and $\psi$ are the rotation angle of the block and roller, and $\Delta_{0}, h_{k}$ are the preload, roller profile, respectively.

In order to investigate the guide rail error effect on the roller-rail contact, the guide rail error shown in Fig. 3 is considered. The applied guide rail error is a sinusoidal wave with the period of $J_{L}$ and the amplitude of $\delta$. An offset of $\delta$ is also applied to account for compression due to bolting. The guide rail error was converted through the transformation matrix to apply the roller-rail contact in the local coordinate system. Then, the roller-rail compression considering the guide rail error is as follows:

$$
e(z)=R_{R} E(z)
$$

$$
\Delta_{k}=v_{\xi}-e_{\xi}(z)+\psi l_{k}+\Delta_{0}-h_{k}
$$

\section{Iv. Analysis of linear bearing for guide rail error and vertical load}

Table 1 shows the parameters of the linear roller bearings used in the simulation. The position where the load is applied is the center of the top surface of the carriage. The function for the guide rail error is as follows.

$$
E(z)=\delta\left(\sin \left(2 \pi\left(\frac{z}{J_{L}}-\frac{1}{4}\right)\right)+1\right)
$$


Proc. of the Sixth Intl. Conf. Advances in Civil, Structural and Mechanical Engineering - CSM 2018

Copyright (C) Institute of Research Engineers and Doctors, USA. All rights reserved.

ISBN: 978-1-63248-150-4 doi: 10.15224/978-1-63248-150-4-31
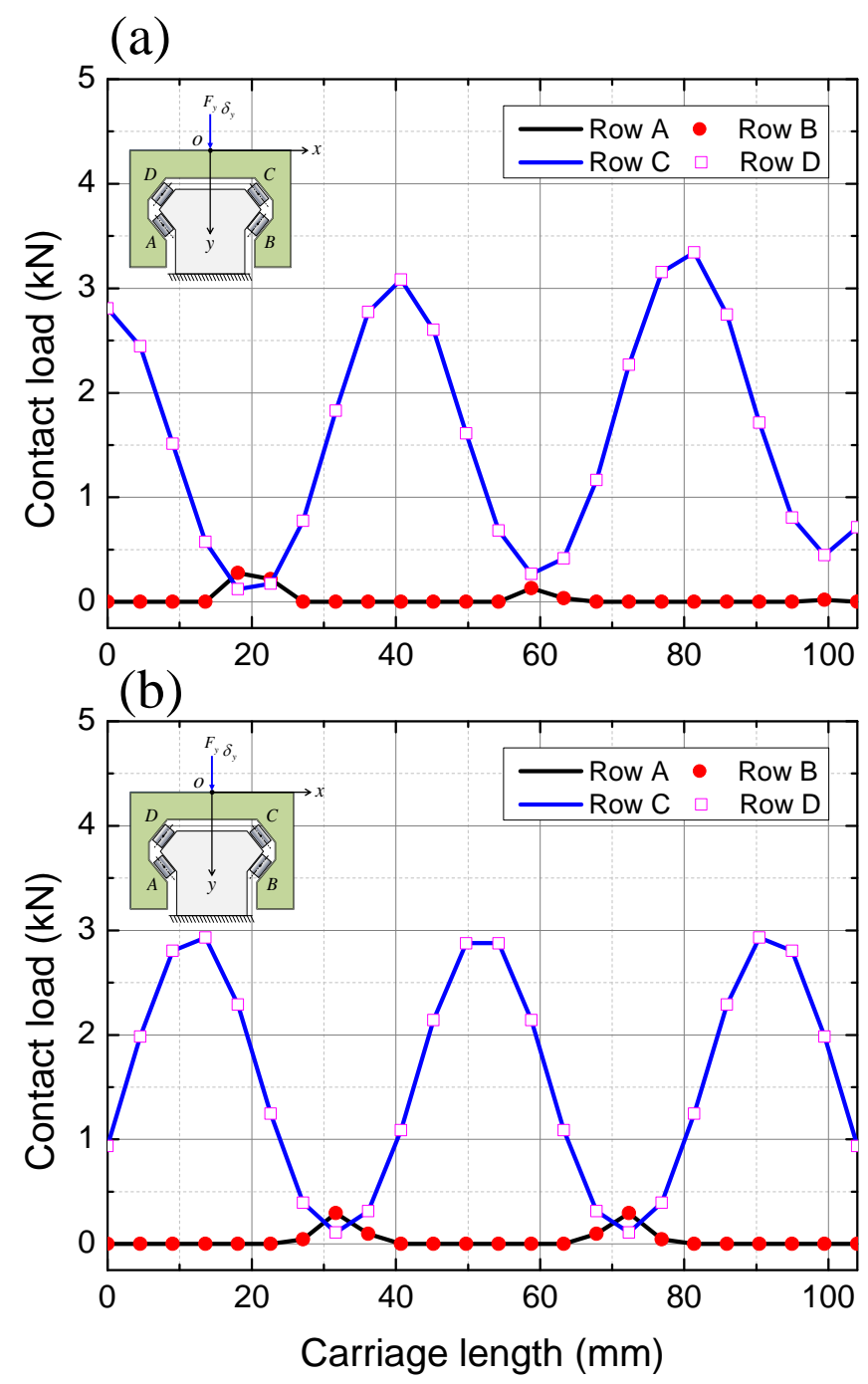

Figure 4. The contact load between roller and carriage due to guide rail error: a) Asymmetric position b) Symmetric position

In this case, the error amplitude $\delta$ is $20 \mu \mathrm{m}$ and the bolting interval $J_{L}$ is $40 \mathrm{~mm}$. Fig. 4 shows the contact load between the roller and carriage when a vertical load of $50 \mathrm{kN}$ is applied to the linear bearing. Because the carriage is subjected to a compressive load in the downward direction, most of the contact loads are concentrated in the upper rows $\mathrm{C}$ and $\mathrm{D}$, and the waveform of the load has the same period as the error of the guide rail. In Fig. 4 (a), it is observed that the contact load gradually increases. In comparison with Fig. 4 (b), it can be estimated that the angular displacement occurs due to the load imbalance depend on the bearing position.

Fig. 5 shows the displacement of the bearing with respect to the vertical load. Because the guide rail error increases for low vertical load, small change occurs in the flexible model, and nonlinearity is not so significant and the displacement is increased in the rigid model. However, under large vertical loads, the displacement of the rigid body model is almost same and the displacement is greatly reduced in the flexible model
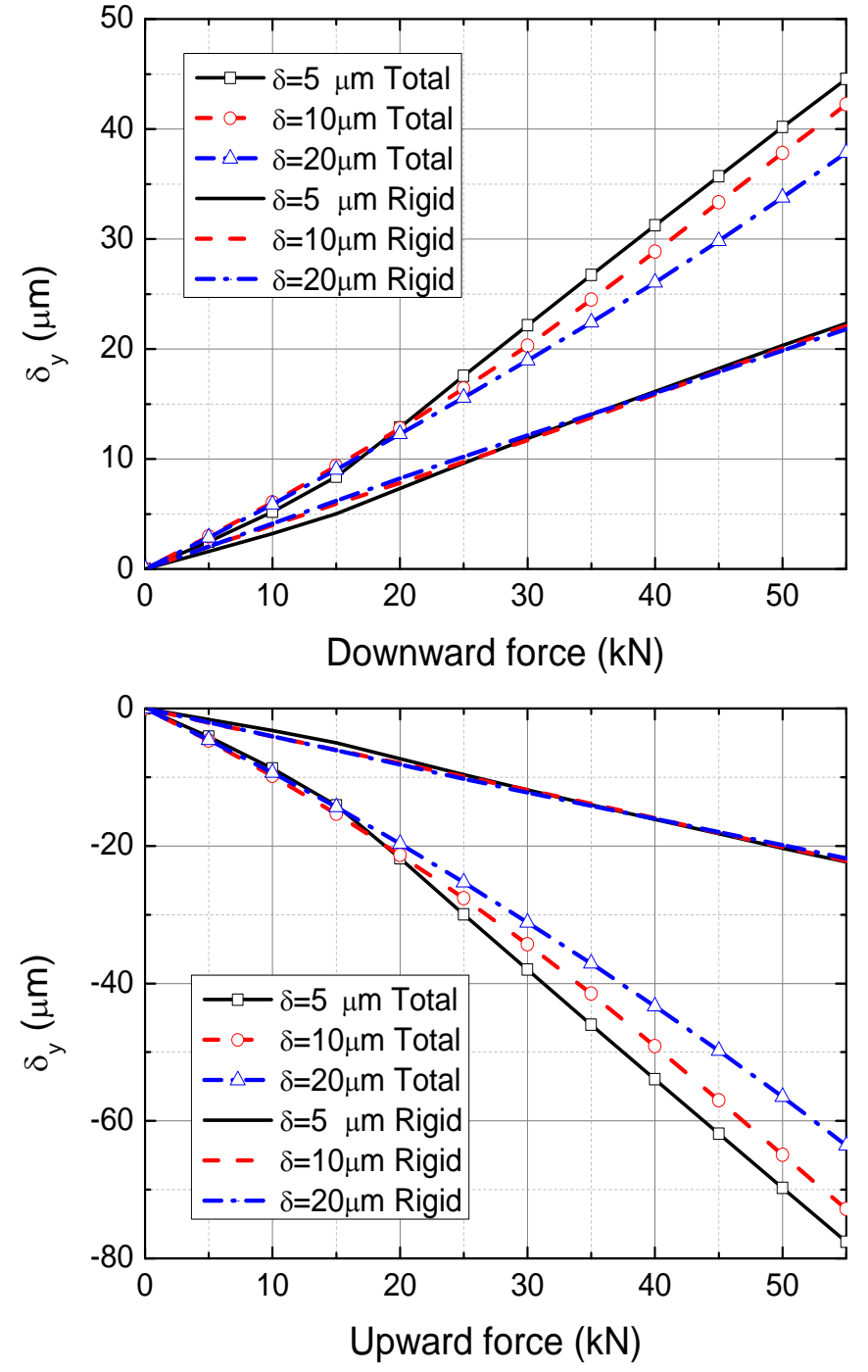

Figure 5. Displacement under vertical load in bearing model with guide rail error

\section{v. Analysis of motion error due to guide rail error}

Fig. 6 is the displacement when the linear bearing moves $80 \mathrm{~mm}$ under $50 \mathrm{kN}$ vertical load. The guide rail error of amplitude 20um and the period of $40 \mathrm{~mm}$ were applied. When there is an error in the rail, the displacement increases proportionally to the amplitude of the rail error. It can be seen that the displacement changes in the same cycle as the rail error.

Because the difference between the bearing displacement and the displacement of the rigid body model remains constant regardless of the amount of error, only the rigid body model is considered for further simulation with regard to error and period. In order to analyze the characteristics according to the bolting interval, the displacement according to the period of the rail error is simulated as shown in Fig. 6. 


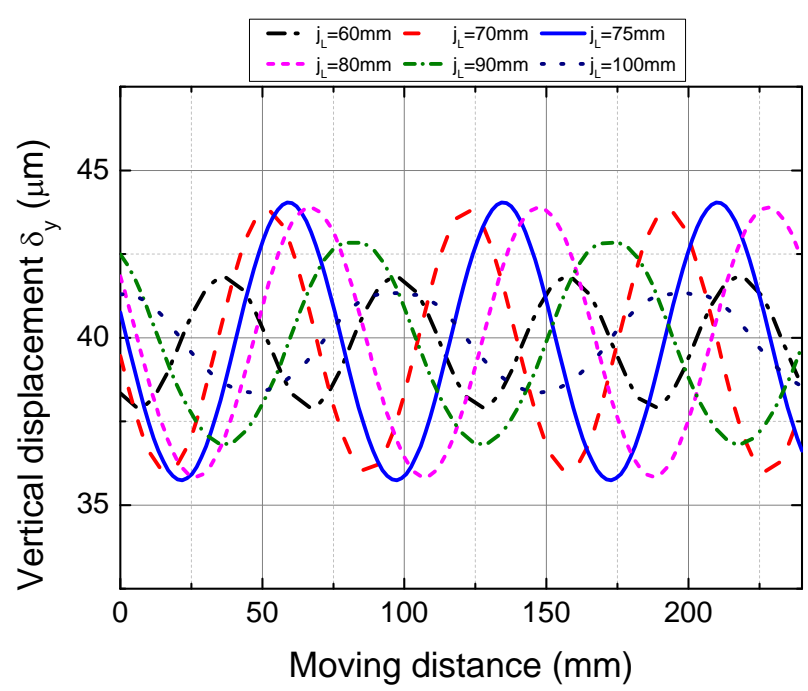

Figure 6. Displacement of the bearing according to the guide rails error period change

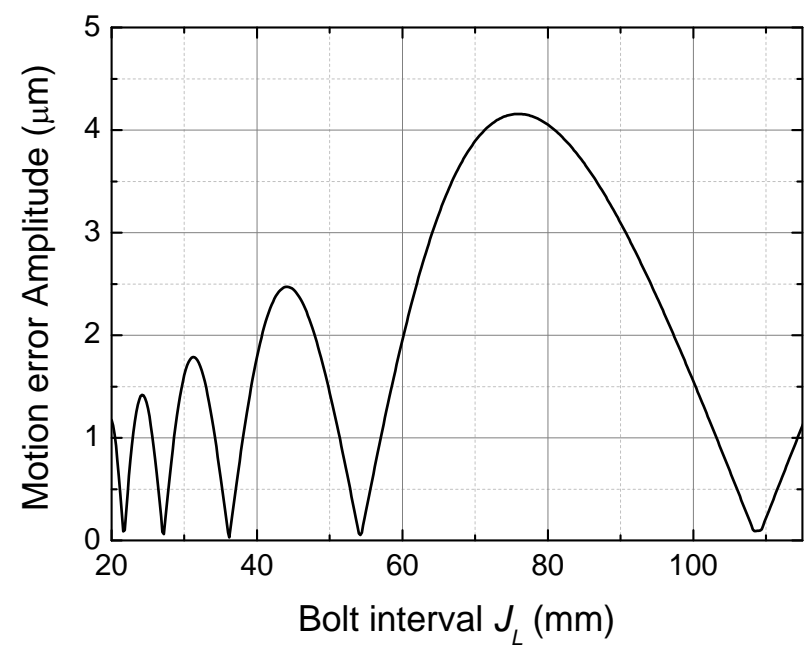

Figure 7. Motion error according to the guide rails error period change

The amplitude of the motion error in the rail error period $J_{L}$ from 20 to $120 \mathrm{~mm}$ was calculated for rigorous characterization. As can be seen in the figure, the amplitude is maximum at $J_{L}=75 \mathrm{~mm}$. Fig. 7 shows the motion error associated with bolting interval. the motion error becomes zero or local maximum at many points. The displacement motion error associated with guide waviness error can be reduced by placing the bolts at appropriate intervals when the displacement motion error in the linear roller bearing is essential.

\section{Conclusions}

In this paper, the characteristics of motion errors in linear roller bearings with guide rail error have been studied. To this end, sine wave rail error was applied by modifying the linear bearing model that took into account the deformations in the contact surfaces and the carriage. The contact load distribution was calculated in the presence of the guide rail error. It was shown that asymmetry of the contact load could occur depending on the position of the carriage. As the guide rail error increases, the vertical stiffness tends to increase. The displacement motion error associated with bolting induced guide rail error can be reduced by placing the bolts at appropriate intervals.

\section{Acknowledgment}

This research was financially supported by Korea Institute for Advancement of Technology (KIAT) through the Encouragement Program for the Industries of Economic Cooperation Region.

\section{References}

[1] P. Majda, "Modeling of geometric errors of linear guideway and their influence on joint kinematic error in machine tools," Precision Engineering Vol. 36.3, pp. 369-378, 2012

[2] G. Khim, C. H. Park, E. Shamoto, and S. W. Kim, "Prediction and compensation of motion accuracy in a linear motion bearing table," Precision Engineering, vol. 35.3, pp. 393-399, 2011.

[3] S. W. Kwon, V. C. Tong, S. W. Hong, "Modeling of displacement of linear roller bearing subjected to external forces considering LM block," Trans. Korean Soc. Mech. Eng. A, Vol. 40, No. 12, pp. 1077-1085, 2016.

[4] P. Zhang, et. al, "Influence of geometric errors of guide rails and table on motion errors of hydrostatic guideways under quasi-static condition," International Journal of Machine Tools and Manufacture, Vol. 125, pp. $55-67,2018$

[5] INA, 2012, "Monorail guidance systems - Linear recirculating roller bearing and guideway assemblies linear recirculating ball bearing and guideway assemblies linear guidance systems with linear recirculating ball bearing units accessories."

[6] M.J. Hartnett, C.J. Robinson and E.B. Tharp, 1984, "Roller Bearing with Specially Constructed Rollers," U.S. Patent, No. 4,456,313.

[7] T.A. Harris and M.N. Katzalas, "Rolling Bearing Analysis," CRC Taylor \& Francis, Vol. 2, pp. 13, 2006

[8] G. Lundberg, "Elastic contact between two semi-infinite bodies," Forschung auf den Gebiete des Ingenieurwesen, Vol. 10, No. 5, pp. 201 211, 1939 